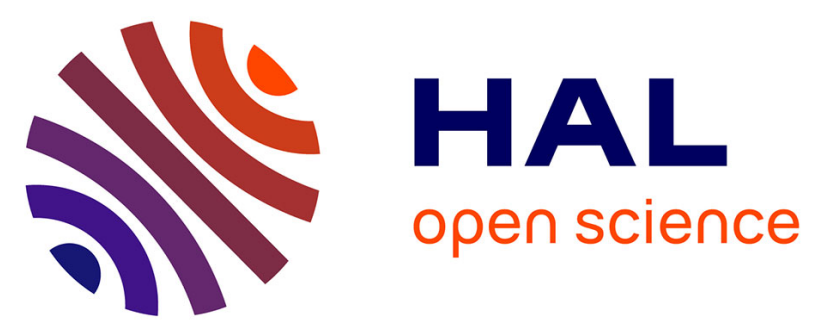

\title{
Assessment of Ancillary Service Demand Response and Time of Use in a Market-Based Power System Through a Stochastic Security Constrained Unit Commitment
}

Saber Talari, Miadreza Shafie-Khah, Neda Hajibandeh, João Catalão

\section{- To cite this version:}

Saber Talari, Miadreza Shafie-Khah, Neda Hajibandeh, João Catalão. Assessment of Ancillary Service Demand Response and Time of Use in a Market-Based Power System Through a Stochastic Security Constrained Unit Commitment. 8th Doctoral Conference on Computing, Electrical and Industrial Systems (DoCEIS), May 2017, Costa de Caparica, Portugal. pp.233-241, 10.1007/978-3-319-56077$9 \_22$. hal-01629577

\section{HAL Id: hal-01629577 \\ https://hal.inria.fr/hal-01629577}

Submitted on 6 Nov 2017

HAL is a multi-disciplinary open access archive for the deposit and dissemination of scientific research documents, whether they are published or not. The documents may come from teaching and research institutions in France or abroad, or from public or private research centers.
L'archive ouverte pluridisciplinaire HAL, est destinée au dépôt et à la diffusion de documents scientifiques de niveau recherche, publiés ou non, émanant des établissements d'enseignement et de recherche français ou étrangers, des laboratoires publics ou privés.

\section{(c)(1)}

Distributed under a Creative Commons Attribution| 4.0 International License 


\title{
Assessment of Ancillary Service Demand Response and Time of Use in a Market-based Power System through a Stochastic Security Constrained Unit Commitment
}

\author{
Saber Talari ${ }^{1}$, Miadreza Shafie-khah ${ }^{1}$, Neda Hajibandeh ${ }^{1}$ and João P.S. Catalão ${ }^{1,2,3}$ \\ ${ }^{1}$ C-MAST, University of Beira Interior, Covilhã 6201-001, Portugal \\ 2 INESC TEC and the Faculty of Engineering of the University of Porto, Porto 4200-465 \\ ${ }^{3}$ INESC-ID, Instituto Superior Técnico, University of Lisbon, Lisbon 1049-001, Portugal \\ saber.talari@ubi.pt; miadreza@ubi.pt; hajibandeh.n@ubi.pt; catalao@fe.up.pt
}

\begin{abstract}
In this paper, the impacts of an incentive-based Demand Response, i.e., Ancillary Service DR (ASDR), and a price-based DR, i.e., Time of Use $(\mathrm{ToU})$, are revealed in a restructured power system which has some wind farms. This network is designed based on the pre-emptive market which is a day-ahead market with a balancing market prognosis. It is a proper mechanism to deal with the stochastic nature of non-dispatchable and outage of all units of the network. With Monte Carlo Simulation (MCS) method, several scenarios are generated in order to tackle the variability and uncertainties of the wind farms generation. The impacts of merging ASDR and ToU are investigated through running a two-stage stochastic security constrained unit commitment (SCUC), separately.
\end{abstract}

Keywords: Ancillary service demand response, security constrained unit commitment, time of use, two-stage stochastic programming.

\section{Introduction}

With the increasing of these renewable energy resources in the power systems, Independent System Operators (ISO) have been faced with new challenges, mainly related to the random and uncertain nature of wind speed [1-2].

On the other hand, with growing the share of wind energy in power system's energy, novel methods have been proposed to improve the power consumption pattern of consumers [3]. Demand Response Programs (DRPs) are one of the most practical methods for this purpose.

With the expansion of smart meters, like Advanced Metering Infrastructure (AMI) and Internet of Things (IoT), in demand side of power systems, implementation of different methods of Demand Response (DR) is going to be much more applicable [4-5]. A suitable DR method can not only decrease total operation cost but also provide security and safety of the network operation [6]. 
In [7], an approach is proposed for shifting suitable amount of load from peak hours to off-peak hours to facilitate effective use of wind generators, reduce possible contingencies in the network and nonnegative local marginal prices (LMP).

Transferring and load shifting has been performed for those loads that can be moved from peak hours to off-peak hours under the load control of Independent System Operator (ISO), while the total load over the planning horizon is completely fixed. Load shifting of the consumers from peak hours to off-peak hours has been conducted by implementing Incentive Based Demand Response (IBDR) programs where only one of the incentive demand response programs has been modeled. By implementing several programs of demand response programs and using time-based demand response programs, more reliable results will be presented.

In [8], wind resources have been used for the flexibility of supply side and their uncertainties have been considered. A flexible stochastic security-constrained shedding framework has been presented for simultaneous optimization of utilization in the supply and demand side aided a demand response plan or program named Time of Use (TOU) optimization tariff [9]. In [10-12], TOU tariffs have been optimized so that the flexibility potential of load side in confronting with the load uncertainty and large scale changes of generation side is maximized. In [13-14], the impact of two important demand response strategies of Load curtailment and Load shifting on power systems with the wind generation has been investigated. In [15] the problem of constructing the bidding curve has been discussed for a retailer to offer in the pool market. The problem is formulated as a stochastic linear programming.

In this paper, the impacts of Ancillary Service DR (ASDR) and Time of Use (ToU) are studied. A day-ahead market with a balancing market is considered. With a Monte Carlo Simulation (MCS) method, several scenarios are generated in order to tackle the variability and uncertainties of wind generation. The impacts of merging ASDR and ToU are thoroughly investigated.

\section{Relationship to Smart Systems}

The various current facilities in smart grids either in terms of communication technology e.g. Home Area Networks (HAN) or smart meters e.g. advanced metering infrastructures (AMI) enable end-users to participate actively in electricity market in order to improve security, economy, efficiency and reliability of network operation [16]. The information flow in the smart grids can be classified based on power flow and power system sections. Accordingly, communication architecture for demand response is introduced. Home Area Networks/Business Area Networks/Industrial Area Networks (HANs/BANs/IANs) are communication technologies which are deployed in residential units, commercial buildings, and industrial plants in order for connecting multiple electrical appliances to smart meter through $\mathrm{ZigBee}$, WiFi, or Power-line communication (PLC) [17].

On the other hands, Neighborhood Area Networks/Field Area networks (NANs/FANs) are designed for communication between different smart meters of power distribution system through Data aggregate Unit (DAU), WiFi, world-wide interoperability for microwave access (WiMax) or cellular networks like GPRS, 3G 
and LTE. Meanwhile, for communication between bulk generation, transmission lines (Wide-Area Network) WANs is used through fiber-optic communication or microwave transmission.

\section{Formulation}

In this paper, two objective functions are introduced in order to deal with both pricedbased demand response that is ToU and incentive-based demand response which is ASDR. In fact, for the earlier, a two-stage stochastic program is run for maximizing social welfare and the later, a two stage-stochastic program is run for minimizing total operation cost. Some amount of customers' consumption in ToU program are presented as load bidders. Hence, the objective is to maximize deference of end-user cost and operation cost. Accordingly, the objective function for ToU program and their constraints are shown as follows:

$\operatorname{Max} \sum_{t=1}^{T}\left\{\begin{array}{l}\sum_{b=1}^{B}\left\{\left(\operatorname{Bid}_{b, t} \operatorname{DisL}_{b, t}\right)-\sum_{n=1}^{N}\left(P_{n, t} B_{n, t}+C_{n, t}^{U p} \operatorname{SR}_{n, t}^{U p}+C_{n, t}^{\text {Down }} \operatorname{SR}_{n, t}^{\text {Down }}+S U_{n} y_{n, t}+S D_{n} z_{n, t}\right)\right. \\ \left.+\sum_{s=1}^{S}\left(\operatorname{Pr}_{t, s} \times\left(\sum_{n=1}^{N} r_{s, n, t}^{u p} \times \operatorname{res} C_{n}^{u p}+r_{s, n, t}^{\text {down }} \times \operatorname{res} C_{n}^{\text {down }}\right)+\sum_{b=1}^{B} V O L L \times \text { Lshed }_{s, b, t}\right)\right\}\end{array}\right.$

In this formulation, the first line is regarding first stage where Bid $_{b, t}$, is load bidding at hour $\mathrm{t}$ and bus $\mathrm{b}, \operatorname{Dis}_{b, t}$, is the dispatched load at hour $\mathrm{t}$ and bus $\mathrm{b}$. Moreover, $P_{n, t} B_{n, t}$ is cost of scheduled power production of unit $\mathrm{n}$ at hour $\mathrm{t}$. $C_{n, t}^{U p} S R_{n, t}^{U p}, C_{n, t}^{\text {Down }} S R_{n, t}^{\text {Down }}$ are cost of scheduled up-spinning reserve and down-spinning reserve of unit $\mathrm{n}$ at hour $\mathrm{t}$, respectively. $S U_{n}, S D_{n}$ are the start-up cost and shut-down cost of unit $n$, respectively. The second line is related to second stage which handles the balance market by different scenarios where $\operatorname{Pr}_{t, s}$, is the probability of scenario $\mathrm{s}$ at time $\mathrm{t}, \quad r_{s, n, t}^{u p} \times \operatorname{res} C_{n}^{u p}$ is the cost of scheduled up-spinning reserve of unit $\mathrm{n}$ at scenario $\mathrm{s}, r_{s, n, t}^{\text {down }} \times \operatorname{res} C_{n}^{\text {down }}$ is the cost of scheduled down-spinning reserve of unit $\mathrm{n}$ at scenario s. The last term $V O L L \times$ Lshed $_{s, n, t}$ is the cost of forced load curtailment at bus $\mathrm{n}$ and scenario $\mathrm{s}$ and hour $\mathrm{t}$.

Subject to:

DC power flow equation

$$
\sum_{n=1}^{N} P_{n, t}+W_{b, t}^{\text {dispach }}=\mu \sum_{b=1}^{B} L d_{b, t}+\sum_{l=1}^{L} \text { Pflow }_{l, t}
$$


where, $W_{b, t}^{\text {dispach }}$ is the real power usage from wind farm node $\mathrm{n}$ at hour $\mathrm{t}$ which should be less than $W_{b, t}^{\text {expect }}$ (the expected produced power from wind farm of node $\mathrm{n}$ at hour $\mathrm{t}$ ), $L d_{b, t}$ is the whole demand at bus b and hour $\mathrm{t}, \mu$ is the percentage of the load which must be feed and are not placed in ToU program, Pflow ${ }_{l, t}$ is real power flow in line $l$ and hour t which is as follows:

$$
\text { Pflow }_{l}=\frac{1}{X_{l}}\left(\delta_{l s}-\delta_{l r}\right)
$$

where $X_{l}$ is reactance of line $l, \delta_{l s}$ is voltage angle of sending-end bus of line $l$ and $\delta_{l r}$ is voltage angle of receiving-end bus of line $l$ and its constraint is as follows:

$$
- \text { Pflow }_{l, t}^{\max } \leq \text { Pflow }_{l, t} \leq \text { Pflow }_{l, t}^{\max }
$$

where Pflow ${ }_{l, t}^{\max }$ is the maximum capacity of line $l$. And the real power generation constraints are as follows:

$$
p_{n}^{\min } \cdot u_{n, t}+S R_{n, t}^{\text {Down }} \leq p_{n, t} \leq p_{n}^{\max } u_{n, t}-S R_{n, t}^{U p}
$$

where $p_{n}^{\min }, p_{n}^{\max }$ are the minimum and maximum capacity of unit $\mathrm{n}, u_{n, t}$ is the commitment state of unit $\mathrm{n}$ at hour t. Moreover, start-up and shut-down constraint of units are as follows:

$$
\begin{aligned}
& u_{n, t}-u_{n, t-1}=y_{n, t}-z_{n, t} \\
& y_{n, t}+z_{n, t} \leq 1
\end{aligned}
$$

Up and down spinning reserve constraints are as follows:

$$
\begin{aligned}
& 0 \leq S R_{n, t}^{U p} \leq R_{n}^{u p} \\
& 0 \leq S R_{n, t}^{\text {Down }} \leq R_{n}^{\text {down }}
\end{aligned}
$$

where $R_{n}^{u p}$ is ramp-up limitation for unit $\mathrm{n}$ and $R_{n}^{\text {down }}$ is ramp-down limitation for unit n. Plus, ramp-up and -down constraints are as follows:

$$
\begin{aligned}
& P_{n, t}-P_{n, t-1} \leq R_{n}^{\text {down }} \\
& P_{n, t-1}-P_{n, t} \leq R_{n}^{u p}
\end{aligned}
$$


Constraints of second stage include DC power flow equation which is as follows:

$$
\sum_{n=1}^{N} u s_{s, n, t} P_{n, t}+r_{s, n, t}^{u p}-r_{s, n, t}^{\text {down }}+W_{s, b, t}^{\text {scen }}-W_{s, b, t}^{\text {spill }}=\mu \sum_{b=1}^{B} L d_{b, t}+\sum_{l=1}^{L} \text { Pflow }_{s, l, t}-\text { Lshed }_{s, b, t}
$$

where $u s_{s, n, t}$ is the given state of unit $\mathrm{n}$ at scenario $\mathrm{s}$ and hour $\mathrm{t}, W_{s, n, t}^{\text {scen }}$ is the amount of produced power by wind farm node $\mathrm{b}$ in scenario $\mathrm{s}$ and hour $\mathrm{t}, W_{s, b, t}^{\text {spill }}$ is the spillage power of wind farm node $\mathrm{b}$ in scenario $\mathrm{s}$ and hour $\mathrm{t}$, Pflow $_{s, l, t}$ is power flow of line $l$ in scenario s and hour $\mathrm{t}$ which is as follows:

$$
\text { Pflow }_{l, s}=\frac{1}{X_{l}}\left(\delta_{s, l s}-\delta_{s, l r}\right)
$$

where $\delta_{s, l s}$ is voltage angle of sending-end bus of line $l$ in scenario s and $\delta_{s, l r}$ is voltage angle of receiving-end bus of line $l$ and its constraint is as follows:

$$
- \text { Pflow }_{l, t}^{\max } \leq \text { Pflow }_{s, l, t} \leq \text { Pflow }_{l, t}{ }^{\max }
$$

The deployed up- and down-spinning reserve constraints are as follows:

$$
\begin{aligned}
& 0 \leq s r_{s, n, t}^{U p} \leq u s_{s, n, t} S R_{n, t}^{U p} \\
& 0 \leq s r_{s, n, t}^{\text {Down }} \leq u s_{s, n, t} S R_{n, t}^{\text {Down }}
\end{aligned}
$$

Finally, the maximum load that is participated in this demand response program should be specified as follows:

$$
\operatorname{Dis} L_{b, t} \leq \lambda \times L d_{b, t}
$$

where $\lambda$ is the percentage of the load at bus $b$ that should be joined in DRP.

On the other hands, the objective function for ASDR and some constraints have a few differences compared with ToU. In this program, total operation cost will be minimized and demand response is scheduled as a reserve for the loads which participate in this program. the objective function is as follows:

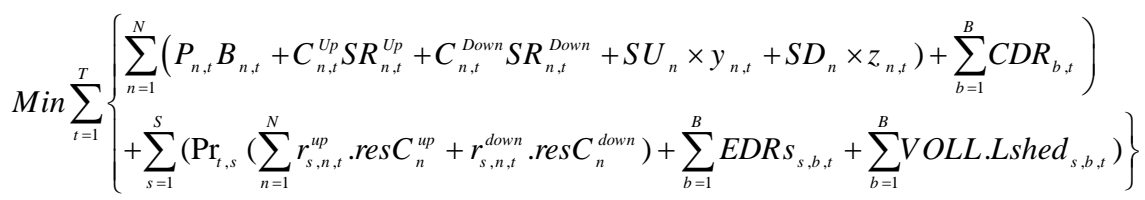


where $C D R_{b, t}$ is the capacity cost of scheduled demand response reserve for load of bus $\mathrm{b}$ at hour $\mathrm{t}$ and $E D R s_{s, b, t}$ is the energy cost of scheduled demand response reserve for load of bus $\mathrm{b}$ in scenario $\mathrm{s}$ and at hour $\mathrm{t}$ which are defined as follows:

$$
\begin{aligned}
& D R_{b, t}=q_{b, t}^{0} u_{b, t}^{0}+\sum_{k=1}^{K} \lambda_{b, t}^{k} u_{b, t}^{k} \\
& C D R_{b, t}=c c_{b, t}^{0} q_{b, t}^{0} u_{b, t}^{0}+\sum_{k=1}^{K} c c_{b, t}^{k} \lambda_{b, t}^{k} u_{b, t}^{k} \\
& \lambda_{b, t}^{k}=q_{b, t}^{k}-q_{b, t}^{k-1}
\end{aligned}
$$

In this program, several demand response discrete points $\mathrm{k}$ is determined as $q_{b, t}^{k}$ for bus $\mathrm{b}$ and hour $\mathrm{t}$ and each discrete point $\mathrm{k}$ has a capacity $\operatorname{cost} c c_{b, t}^{k}$. The first $\mathrm{k}$ is separated and the difference of next $\mathrm{k}$ and previous one is assigned as $\lambda_{b, t}^{k}$ with specific price of $c c_{b, t}^{k}$. Each level can be selected by the objective function based on profitability. The state of which level $\mathrm{k}$ at bus $\mathrm{b}$ and hour $\mathrm{t}$ is being deployed is determined as $u_{b, t}^{k}$. This program is almost the same in second stage which is as follows:

$$
\begin{aligned}
& 0 \leq d r_{s, b, t} \leq D R_{b, t} \\
& d r_{s, b, t}=q_{b, t}^{0} u k_{s, b, t}^{0}+\sum_{k=1}^{K} \lambda_{s, b, t}^{k} u k_{s, b, t}^{k} \\
& E D R s_{s, b, t}=e c_{b, t}^{0} q_{b, t}^{0} u k_{s, b, t}^{0}+\sum_{k=1}^{K} e c_{b, t}^{k} \lambda_{b, t}^{k} u k_{s, b, t}^{k}
\end{aligned}
$$

where $e c_{b, t}^{k}$ is the energy cost of demand response reserve in scenarios and $u k_{s, b, t}^{k}$ is the state of which level $\mathrm{k}$ at bus $\mathrm{b}$ and hour $\mathrm{t}$ in scenario $\mathrm{s}$ is being deployed. $d r_{s, b, t}$ is scheduled demand response reserve of bus $b$ in scenario $s$ at hour $t$. Some of the constraints are different from the ToU program that are as follows:

$$
\begin{aligned}
& \sum_{n=1}^{N} P_{n, t}+W_{b, t}^{\text {dispach }}=\sum_{b=1}^{B} L d_{b, t}+\sum_{l=1}^{L} \text { Pflow }_{l, t} \\
& \sum_{n=1}^{N} u s_{s, n, t} P_{n, t}+r_{s, n, t}^{u p}-r_{s, n, t}^{\text {down }}+W_{s, b, t}^{\text {scen }}-W_{s, b, t}^{s p i l l}+\sum_{b=1}^{B} d r_{s, b, t}=\sum_{b=1}^{B} L d_{b, t}+\sum_{l=1}^{L} \text { Pflow }_{s, l, t}-\text { Lshed }_{s, b, t}
\end{aligned}
$$




\section{Case Study}

The 14-bus IEEE power system is used in this study. The slack bus of system is node1. Two wind farms are connected to the power system at Node 5 and Node8. The capacity of each one is equal to $100 \mathrm{MW}$. Here are several scenarios that each trajectory is the sum of power production of two nodes. There are four cases to assess running ToU and ASDR and compare them in terms of efficiency. First case is running a stochastic SCUC to maximize social welfare without participating loads as ToU DRP and with a constant tariff for load bidding $B i d_{b, t}$. The second case is similar to first one with difference of considering $20 \%$ of loads for joining ToU DRP with different tariffs $B i d_{b, t}$. The third case is running a stochastic SCUC to minimize total operation cost without considering ASDR. The fourth case is similar the third one with considering $20 \%$ of loads to join ASDR program. In the first case, it is assumed that load bidding is $50 \$ / \mathrm{MWh}$ for all hours. In the second case, two tariff levels are defined for ToU. For peak hours e.g. 13-20 and 28-45, tariff is $40 \$ / \mathrm{MWh}$ and for others tariff is $70 \$ / \mathrm{MWh}$. Accordingly, social welfare for each hour is obtained and it is shown in Fig. 1 . As can be seen, in case 2 where the ToU is used the social welfare is mostly higher than case 1, especially in peak times. Moreover, in Fig. 2 which shows the amount of DR participated loads that are supplied. As can be seen, some of loads at peak hours are not supplied in order to get higher social welfare. For the third and fourth cases, demand response is applied just for node 3 and 4. Furthermore, information of ASDR is shown in Table. 1. As can be seen in Fig.3, the operation cost of forth case at hours 34-38 and hour 42 is lower than the case without ASDR. Because, demand response is just scheduled for load in node 4 at hour 34-38 and hour 42. Therefore, the operation cost at these hours are less than operation cost without considering ASDR. Table 2 shows cost of reserve-up, reserve-down, power production units, and security cost which is related to balancing market for all four case studies. The total cost case 1 which is social welfare is lower than case 2 because of using ToU in second one. Finally, total operation cost for case 4 is lower than case 3 because of using ASDR in fourth case.

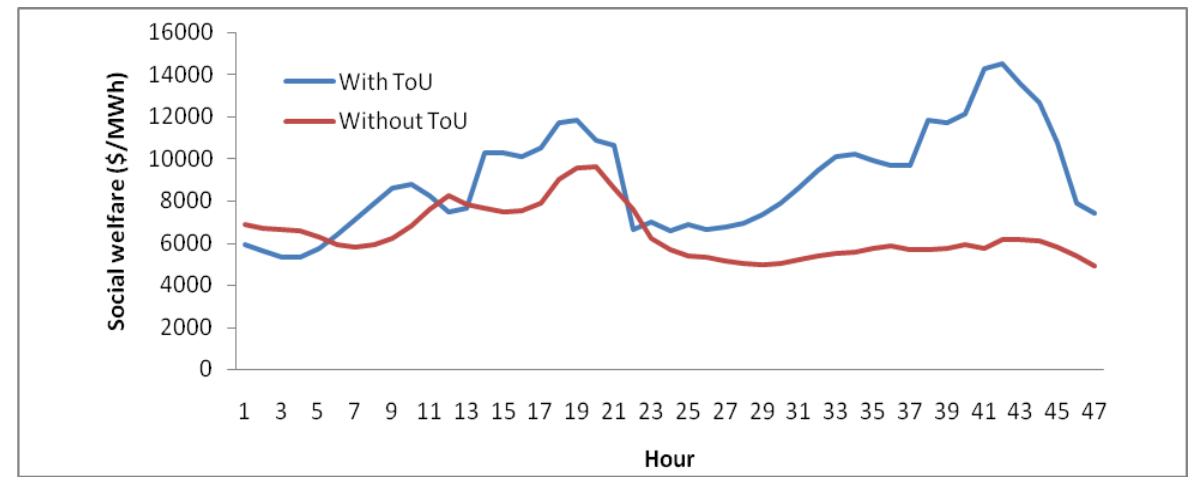

Fig.1 social welfare for case 1 and 2 at each hour 


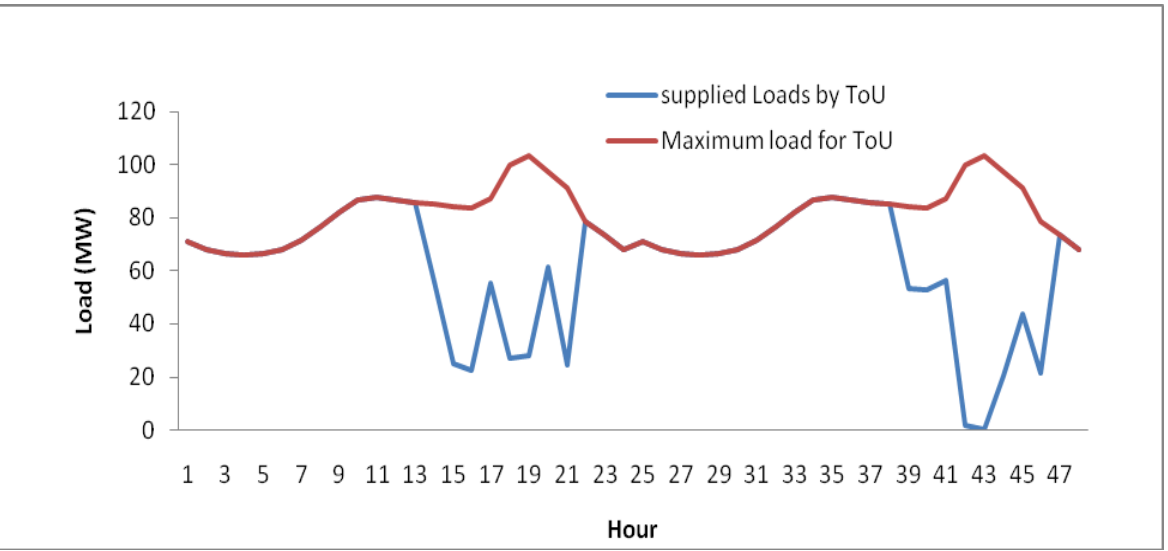

Fig.2 Maximum load for joining ToU and the amount of supplied loads within ToU program

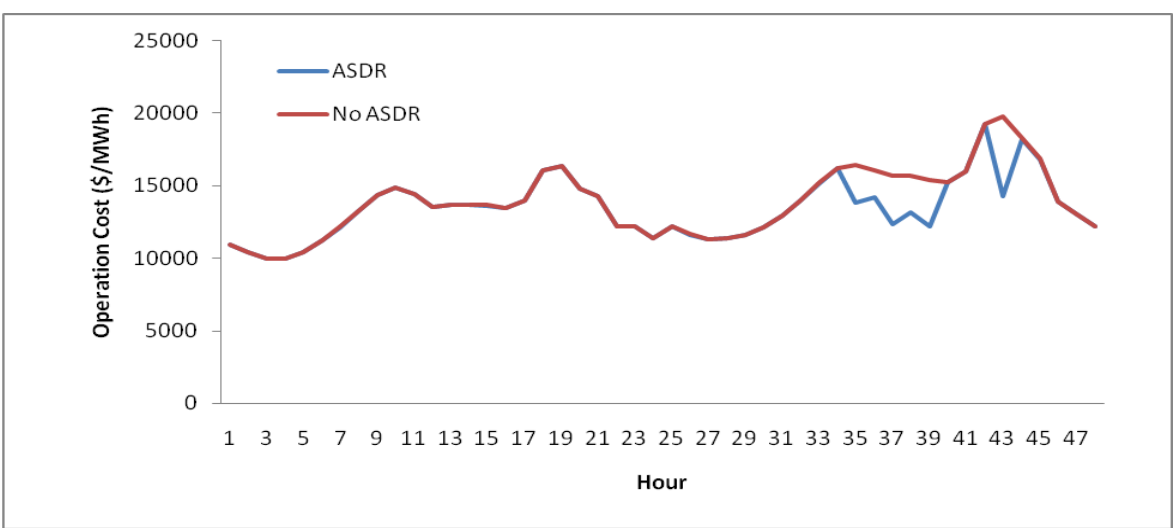

Fig.3 Hourly operation cost for case 3 and 4

Table. 1 ASDR data

\begin{tabular}{l|l|l|l|l}
\hline $\mathrm{k}$ & 0 & 1 & 2 & 3 \\
\hline$q_{t}^{k}(M W)$ & 20 & 30 & 40 & 50 \\
\hline$c c_{t}^{k}(\$ / M W h)$ & 10 & 12.5 & 15 & 17.5 \\
\hline$e c_{t}^{k}(\$ / M W h)$ & 20 & 22.5 & 25 & 27.5 \\
\hline
\end{tabular}


Table.2 Different costs of 4 case studies

\begin{tabular}{c|c|c|c|c}
\hline & $\begin{array}{c}\text { Case1- } \\
\text { Base ToU }\end{array}$ & $\begin{array}{c}\text { Case2- } \\
\text { ToU }\end{array}$ & $\begin{array}{c}\text { Case3- Base } \\
\text { ASDR }\end{array}$ & $\begin{array}{c}\text { Case4- } \\
\text { ASDR }\end{array}$ \\
\hline $\begin{array}{c}\text { Reserve } \\
\text { up } \$)\end{array}$ & 0 & 0 & 0 & 0 \\
\hline $\begin{array}{c}\text { Reserve } \\
\text { down }(\$)\end{array}$ & 34627 & 34521.700 & 34627.000 & 0 \\
\hline $\begin{array}{c}\text { Production } \\
(\$)\end{array}$ & 669670 & 628490 & 669670 & 651300 \\
\hline Security $(\$)$ & 42380 & 42270 & 42380 & 48270 \\
\hline Total $(\$)$ & 306880 & 429770 & 661920 & 651080 \\
\hline
\end{tabular}

\section{Conclusions}

In this paper, the impacts of Ancillary Service DR (ASDR) and Time of Use (ToU) were studied. A day-ahead market with a balancing market was considered. With a Monte Carlo Simulation (MCS) method, several scenarios were generated in order to tackle the variability and uncertainties of wind generation. The impacts of merging ASDR and ToU were thoroughly investigated. The results of this program demonstrate that using demand response program leads to not only compensate wind generators uncertainties but also increase operator benefits. In peak hours, volume of supplied loads will be dropped in both DR programs and social welfare will be higher which means both of operator and customer are more satisfied.

Acknowledgment. This work was supported by FEDER funds through COMPETE 2020 and by Portuguese funds through FCT, under Projects SAICT-PAC/0004/2015 POCI-01-0145-FEDER-016434, POCI-01-0145-FEDER-006961, UID/EEA/50014/2013, UID/CEC/50021/2013, and UID/EMS/00151/2013. Also, the research leading to these results has received funding from the EU Seventh Framework Programme FP7/2007-2013 under grant agreement no. 309048.

\section{References}

1. Jannati M., Hosseinian SH, Vahidi B, Li GJ. A survey on energy storage resources configurations in order to propose an optimum configuration for smoothing fluctuations of future large wind power plants. Renewable and Sustainable Energy Reviews 2014;29:15872 .

2. Zafirakis D, Kaldellis JK. Autonomous dual-mode CAES systems for maximum wind energy contribution in remote island networks. Energy Conversion and Management 2010;51:215061.

3. De Vos K, Petoussis AG, Driesen J, Belmans R. Revision of reserve requirements following wind power integration in island power systems. Renewable Energy 2013;50:268-79. 
4. H. Arasteh et al., "Iot-based smart cities: A survey," 2016 IEEE 16th International Conference on Environment and Electrical Engineering (EEEIC), Florence, 2016, pp. 1-6, doi: 10.1109/EEEIC.2016.7555867

5. F. Kamyab, M. H. Amini, S. Sheykhha, M. Hasanpour, and M.M. Jalali, "Demand response program in smart grid using supply function bidding mechanism," IEEE Transactions on Smart Grid, vol. 7, no. 2, pp. 1277-1284, May 2016.

6. Shahab Bahrami, and Aras Sheikhi. "From demand response in smart grid toward integrated demand response in smart energy hub." IEEE Transactions on Smart Grid 7.2 (2016): 650658 .

7. Sioshansi R, Short W. Evaluating the impacts of real-time pricing on the usage of wind generation. IEEE Trans. Power Syst 2010;24:516-24.

8. Papavasiliou A, Oren S, O, Neill RP. Reserve requirements for wind power integration: A scenario based stochastic programming framework. IEEE Trans. on Power Syst 2011;26:2197-206.

9. E. Heydarian-Forushani, M.E.H. Golshan, M.P. Moghaddam, M. Shafie-khah, and J.P.S. Catalão, "Robust scheduling of variable wind generation by coordination of bulk energy storages and demand response," Energy Conversion and Management 2015;106:941-950.

10. Liu G, Tomsovic K. Quantifying spinning reserve in systems with significant wind power penetration. IEEE Trans. on Power Syst 2012;27:2385-93.

11. Pina A, Silva C, Ferrão P. The impact of demand side management strategies in the penetration of renewable electricity. Energy 2012;41:128-37.

12. E. Heydarian-Forushani, M.E.H Golshan, and M. Shafie-khah, "Flexible SecurityConstrained Scheduling of Wind Power Enabling Time of Use Pricing Scheme," Energy 2015;90:1887-1900.

13. Critz DK, Busche S, Connors S. Power systems balancing with high penetration renewables: The potential of demand response in Hawaii. Energy Conversion and Management 2013;76:609-19.

14. Dietrich K, Latorre JM, Olmos L, Ramos A. Demand response in an isolated system with high wind integration. IEEE Trans. Power Syst 2012;27:20-9.

15. Z. Zhechong, and $\mathrm{L}$. Wu. "Impacts of high penetration wind generation and demand response on LMPs in day-ahead market." Smart Grid, IEEE Transactions on 5.1 (2014): 220-229.

16. K. G. Boroojeni, M. H. Amini, and S.S Iyengar, "Overview of the Security and Privacy Issues in Smart Grids,"Smart Grids: Security and Privacy Issues. Springer Publishing, 2017, pp. 1-16.

17. A. Sheikhi, et al. "A cloud computing framework on demand side management game in smart energy hubs." International Journal of Electrical Power \& Energy Systems 64 (2015): $1007-1016$. 